\title{
openheart Estimated incidence and risk factors of sudden unexpected death
}

\author{
Mary Elizabeth Lewis, ${ }^{1}$ Feng-Chang Lin, ${ }^{2}$ Parin Nanavati, ${ }^{1}$ Neil Mehta, ${ }^{1}$ \\ Louisa Mounsey, ${ }_{1}^{1}$ Anthony Nwosu, ${ }^{1}$ Irion Pursell, ${ }^{1}$ Eugene H Chung, ${ }^{1}$ \\ J Paul Mounsey, ${ }^{1}$ Ross J Simpson $\mathrm{Jr}^{1}$
}

To cite: Lewis ME, Lin F-C, Nanavati P, et al. Estimated incidence and risk factors of sudden unexpected death. Open Heart 2016;3:e000321. doi:10.1136/openhrt-2015000321

Received 28 July 2015 Revised 6 October 2015 Accepted 21 December 2015

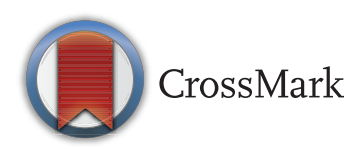

${ }^{1}$ Department of Medicine, The University of North Carolina, Cardiac

Electrophysiology, North Carolina, USA

${ }^{2} \mathrm{NC}$ TraCS, University of North Carolina, North Carolina, USA

Correspondence to Dr Ross J Simpson Jr; ross_simpson@med.unc.edu

\section{ABSTRACT}

Objective: In this manuscript, we estimate the incidence and identify risk factors for sudden unexpected death in a socioeconomically and racially diverse population in one county in North Carolina. Estimates of the incidence and risk factors contributing to sudden death vary widely. The Sudden Unexpected Death in North Carolina (SUDDEN) project is a population-based investigation of the incidence and potential causes of sudden death.

Methods: From 3 March 2013 to 2 March 2014, all out-of-hospital deaths in Wake County, North Carolina, were screened to identify presumed sudden unexpected death among free-living residents between the ages of 18 and 64 years. Death certificate, public and medical records were reviewed and adjudicated to confirm sudden unexpected death cases.

Results: Following adjudication, 190 sudden unexpected deaths including 122 men and 68 women were identified. Estimated incidence was 32.1 per 100000 person-years overall: 42.7 among men and 22.4 among women. The majority of victims were white, unmarried men over age 55 years, with unwitnessed deaths at home. Hypertension and dyslipidaemia were common in men and women. African-American women dying from sudden unexpected death were over-represented. Women who were under age 55 years with coronary disease accounted for over half of female participants with coronary artery disease.

Conclusions: The overall estimated incidence of sudden unexpected death may account for approximately $10 \%$ of all deaths classified as 'natural'. Women have a lower estimated incidence of sudden unexpected death than men. However, we found no major differences in age or comorbidities between men and women. African-Americans and young women with coronary disease are at risk for sudden unexpected death.

\section{INTRODUCTION}

Only about $5 \%$ of victims of out-of-hospital cardiac arrest survive. ${ }^{1}$ Preventing sudden death and unnecessary loss begins with accurately identifying risk factors and potential causes. 'Examining which diseases and injuries result in the greatest number of

\section{KEY QUESTIONS}

What is already known about this subject?

- Sudden death is the leading cause of deaths in adults in the Western world, but current estimates of annual incidence vary widely. A family history of sudden death, depressed left ventricular function, coronary heart disease, hypertension and diabetes mellitus is one of the most important risk factors for sudden death.

What does this study add?

- Previous cohort studies of sudden death victims have been performed on middle-class and largely Caucasian populations. A requirement for known timing of death since last seen alive and free of apparent symptoms may lead to underreporting of cases among socioeconomically diverse populations and minorities. The Sudden Unexpected Death in North Carolina (SUDDEN) project aims to increase our understanding of the causes of sudden death and identify highrisk populations by utilising a prospective, population-based methodology in diverse populations. No time-limiting criteria are required, but deaths must be naturally occurring and unexpected. The results from year 1 of the SUDDEN project show that African-American women and young women with coronary disease are at risk for sudden unexpected death.

How might this impact on clinical practice?

- By identifying vulnerable populations at risk for sudden death, such as African-Americans and young women with coronary disease, clinicians and policymakers will be able to develop appropriate prevention programmes.

deaths in populations, particularly for deaths that occur earlier than expected, allows health officials to establish disease prevention goals, priorities, and strategies, ${ }^{2}-\mathrm{CDC}$ MMWR, 2 May 2014.

The Sudden Unexpected Death in North Carolina (SUDDEN) project is a populationbased investigation of the incidence and causes of all out-of-hospital natural, unexpected deaths within defined populations. 
Cases are recorded regardless of known timing of death or symptom onset, meaning the incidence and causes of sudden death are not prejudged by case selection criteria. ${ }^{4-6}$ Description of significant conditions at the time of death allows for identification of risk factors for sudden death, may lead to policy changes to improve the accuracy of death certificates and other death records and may lead to focused strategies to prevent sudden death. ${ }^{7-10}{ }^{3}$ In the USA and many other industrialised countries, women outlive men and experience fewer cardiovascular events, but the reasons for this enhanced survival are not clear. ${ }^{11} 12$

In this report, we describe differences in incidence and significant conditions by gender over 1 year in one county in North Carolina.

\section{METHODS}

The detailed design and methods of the SUDDEN project have been described previously. ${ }^{6}$ From 3 March 2013 to 2 March 2014, all deaths identified by emergency medical services (EMS) in Wake County, North Carolina, of persons between ages 18 and 64 years were screened to identify presumed sudden unexpected death (SUD) victims. We excluded those who survived to hospital, experienced an expected death or traumatic death or who were not residents of Wake County, North Carolina (figure 1).

A committee of 3 cardiologists unaffiliated with the study, selected for each case at random from a panel of 10 cardiologists, adjudicated 190 participants into the SUDDEN cohort based on available EMS narrative, medical records (hospital or physician records within 5 years of death), medical examiner documents and death certificates.

The panel of cardiologists adjudicated presumed cases by excluding subjects who were terminally ill, had a 'do-not-resuscitate' order, resided in a nursing facility or had a lethal toxicology report. Victims were not excluded if they had traumatic injuries secondary to a cardiac aetiology or had a non-lethal toxicology report. There was substantial agreement between the three adjudicators $(\kappa$ value $=0.68$ ). Data and inclusions were verified by standard quality assurance protocols.

Electronic death certificates as well as a copy of the original death certificate from the register of deeds were obtained for all 190 participants, half of which were signed medical examiner cases. Medical records were acquired for $68 \%$ of participants (table 1 ). There were no significant differences by gender in medical record retrieval rates or in the medical examiner cases (table 1).
Figure 1 Excluded and adjudicated male and female referrals-living and deceased participants were referred to the Sudden Unexpected Death in North Carolina (SUDDEN) project by emergency medical services (EMS) based on the search criteria 'presumed cardiac etiology'. Referrals were screened by exclusion criteria, leaving 211 males and 99 females presumed sudden unexpected deaths (SUDs). About $26 \%$ of men and $37 \%$ of women were screened out because they were over the age of 65 years. After medical records and death certificates were obtained for each participant, a committee of three cardiologists adjudicated 122 men (64\%) and 68 women (36\%) into the SUD in North Carolina (SUDDEN) cohort.

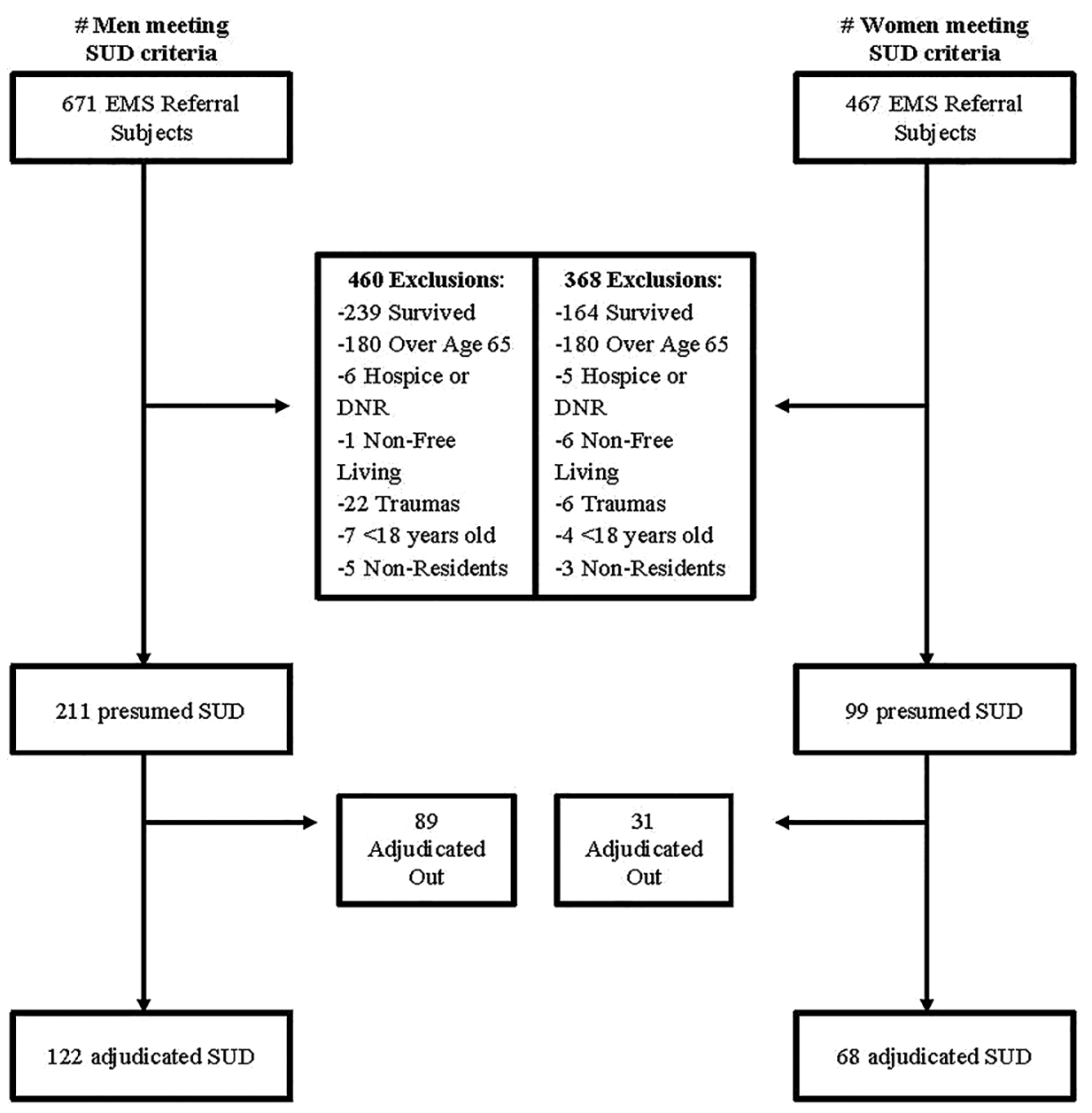


Table 1 Available medical data for SUDDEN men and women

\begin{tabular}{|c|c|c|c|c|}
\hline & Both & Men & Women & $\begin{array}{l}p \\
\text { Value }\end{array}$ \\
\hline $\begin{array}{l}\text { Death } \\
\text { certificate }\end{array}$ & $190(100 \%)$ & $122(100 \%)$ & $68(100 \%)$ & 1.000 \\
\hline $\begin{array}{l}\text { Physician } \\
\text { signed }\end{array}$ & 93 (49\%) & $56(46 \%)$ & 37 (54\%) & 0.291 \\
\hline $\begin{array}{l}\text { Medical } \\
\text { examiner } \\
\text { report }\end{array}$ & 97 (51\%) & $66(54 \%)$ & $31(46 \%)$ & 0.291 \\
\hline $\begin{array}{l}\text { Medical } \\
\text { records }\end{array}$ & 129 (68\%) & $80(66 \%)$ & $49(72 \%)$ & 0.419 \\
\hline
\end{tabular}

Clinical notes were used to determine sudden death risk factors and significant conditions. Age, race, marital status, educational attainment, cause of death and address were noted from North Carolina death certificate data. Location at death and death-witnessed status were obtained from EMS records. Socioeconomic status was estimated by matching the primary residence address to 2010 US Census tract data. Medical records were considered available if the participant had either hospital or physician records within 5 years of death. Medical records were requested for all patients and were provided at the discretion of the collaborating institutions, hospitals or medical practices.

\section{Statistical methods}

Demographics and clinical characteristics of participants are reported in frequency and proportions for categorical variables, and means and SDs for continuous variables. Gender difference in these variables was assessed using Fisher exact tests, $\chi^{2}$ tests or two-sample t tests when appropriate. The same approach compared female participants between SUDDEN victims and total deceased in Wake County and in the living population of Wake County. EMS reports, clinical risk factors and cause of death on death certificate were compared between male and female SUDDEN subjects and reported as ORs with $95 \%$ CIs. Subgroup analysis, stratified by coronary disease as the cause of death, was conducted to explore the difference in death age between males and females. All of the analyses were conducted using SAS V.9.3 (SAS Institute Inc). We consider twosided $\mathrm{p}$ value $<0.05$ statistically significant.

Prior to the analysis, a power analysis determined a total number of 170 participants (85 males and 85 females), assuming an OR of females as $2.5 \%$, and $40 \%$ among those participants with a positive outcome are males, under 0.05 type I error probability and 0.8 statistical power.

\section{RESULTS}

\section{Case selection and demographics}

Excluded subjects had more non-natural causes of death and included subjects had more cardiac causes of death. Nearly $90 \%$ of excluded subjects were medical examiner cases. Compared with excluded subjects, included subjects were older, more commonly female and African-American, and were more likely to have died from non-cardiac natural causes (data not shown).

\section{Main outcome measures}

Figure 2 shows the age distribution of participants by gender and ethnicity, and table 2 compares participants to all decedents and living Wake County residents. Combining the SUDDEN cohort and living Wake County cohort data, the estimated incidence of SUD in the 18-64 age group was 32.1/100 000 of the population and was significantly different between men and women (42.7/100000 among men and 22.4/100000 among women, $\mathrm{OR}=0.53, \mathrm{p}<0.001,95 \%$ CI 0.39 to 0.72 ).

Within the cohort, the average age was 53; 118 participants $(62 \%)$ were Caucasian, $66 \quad(35 \%)$ were African-American, $62(33 \%)$ were married and 128 $(85 \%)$ had graduated high school (table 2). Overall, there were significantly more African-Americans compared to the living Wake County population (35\% vs $21 \%, \mathrm{p}<0.001)$, which is accounted for primarily by a significant excess of African-American women (43\% vs $23 \%, \mathrm{p}<0.001)$ and to a lesser extent by an excess of African-American men (29\% vs $20 \%, \mathrm{p}=0.006)$. Among participants, $122(64 \%)$ were men and $68(36 \%)$ were women, significantly different from the proportions of living men and women in Wake County but not different from 2013 decedents of Wake County.

There was no difference in average age by gender or the proportion of white men and women experiencing SUD (table 2). Figure 2, however, shows that AfricanAmerican men and women were especially overrepresented in the $>55$ age group and under-represented in the 46-55 age group. There is no difference between

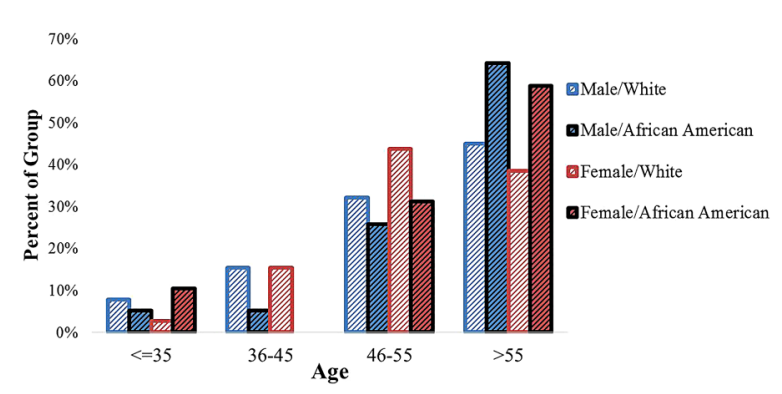

Figure 2 Sudden Unexpected Death in North Carolina (SUDDEN) Gender and Ethnicity by Age-the majority of the cohort is over age 55 years, especially black men but with exception of white women. Each bar represents the percentage of its respective group in each age category. For example, the percentage of white men younger than 35 years constituted $8 \%$ of all white men. 


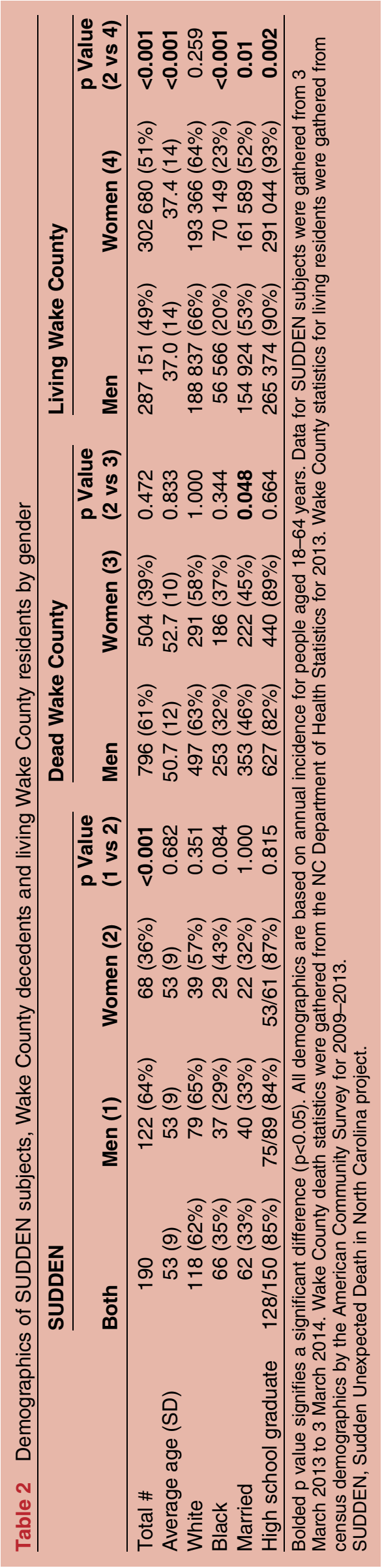

SUDDEN men and women by marital status, annual income below $\$ 50000$ (data not shown) or educational attainment (table 2). Men and women were significantly less likely to be married compared to deceased or living Wake County residents (table $2,33 \%$ vs $46 \%$, $\mathrm{p}=0.018$, vs $53 \%, \mathrm{p}<0.001)$. Men and women were less likely to have graduated high school compared to living Wake County residents (table $2,84 \%$ vs $90 \%, \mathrm{p}=0.008$ ).

\section{Risk factors in men and women}

Table 3 shows that most participants had hypertension. Other common risk factors included dyslipidaemia, smoking and body mass index (BMI) $>30 \mathrm{~kg} / \mathrm{m}^{2}$. Diabetes, cardiomyopathy and coronary artery disease $(\mathrm{CAD})$ are less prevalent in the cohort. There is no statistically significant difference in risk factors between men and women (table 3).

As shown in table 4, 92\% of the cohort was dead on EMS arrival and in 94\% of cases, deaths were unwitnessed. More women than men (99\% vs 91\%) had unwitnessed deaths. Only three married participants (all men) had a witnessed death. Only $32 \%$ of victims were last seen alive within $24 \mathrm{~h}$ of death. In the remainder, the time last seen alive was either unknown or more than $24 \mathrm{~h}$.

The majority had a cardiac cause listed as the immediate (primary) cause of death on their death certificate (table 5). About $37 \%$ had a non-cardiac natural cause listed as their primary cause of death; $4 \%$ were listed as unknown cause of death. There were no cases of substance abuse listed on the death certificate for this cohort. However, medical examiner reports show 29 participants $(31 \%)$ had positive but non-lethal blood or urine levels of one or two of the following: cocaine, opiates, opioids, ethanol, benzodiazepines or amphetamines.

Fewer women had a cardiac cause listed as the primary cause of death on their death certificate, and more women had an unknown cause of death compared with men (table 5). There was no significant difference between the proportions of men and women with a noncardiac natural cause of death listed as the primary cause of death on their death certificate (table 5).

Death certificates were more likely to attribute older men's and women's deaths to CAD, especially for older women. However, medical records and medical examiner reports suggest that younger women were more likely to have CAD as a risk factor than men of the same age (figure 3).

\section{DISCUSSION}

We have developed an ongoing, population-based case registry of SUD in the adult $<65$ population over 12 months in a single North Carolina county. At 1 year of assessment of such victims, we find that the majority of such deaths were unwitnessed and occurred in white, unmarried, hypertensive men with an average age of 
Table 3 Risk factors for men and women from clinical notes of SUDDEN subjects with available medical information

\begin{tabular}{|c|c|c|c|c|c|}
\hline & Both & Men & Women & OR $(95 \% \mathrm{Cl})$ & p Value \\
\hline Available medical information & $181 / 190(95)$ & 116/122 (95) & $65 / 68(96)$ & $1.121(0.238$ to 5.877$)$ & 1.000 \\
\hline Hypertension & $105(58)$ & $65(56)$ & 40 (62) & 1.255 (0.645 to 2.447$)$ & 0.531 \\
\hline Dyslipidaemia & $78(43)$ & $48(41)$ & $30(46)$ & 1.214 (0.629 to 2.344$)$ & 0.534 \\
\hline Smoker & $68(38)$ & 45 (39) & $23(35)$ & $0.864(0.438$ to 1.701$)$ & 0.749 \\
\hline $\mathrm{BMI}>30$ & $59(33)$ & $35(30)$ & $24(38)$ & 1.355 (0.679 to 2.702$)$ & 0.353 \\
\hline Diabetes & $56(31)$ & $32(28)$ & $24(37)$ & 1.537 (0.764 to 3.089$)$ & 0.241 \\
\hline Cardiomyopathy & $46(25)$ & $27(23)$ & $19(29)$ & 1.362 (0.648 to 2.856$)$ & 0.380 \\
\hline CAD & $41(22)$ & $27(23)$ & $14(22)$ & 0.905 (0.408 to 1.992$)$ & 0.855 \\
\hline
\end{tabular}

The values are given as $\mathrm{n}(\%)$. The listed comorbidities were identified as potential sudden unexpected death risk factors by the Oregon study. Medical information was considered available if participants had records from hospital, physician or medical examiner sources. BMI, body mass index; CAD, coronary artery disease; SUDDEN, Sudden Unexpected Death in North Carolina project.

53 years. In comparison with the general population, women were significantly under-represented, and incidence in African-Americans was higher than expected. Younger women with coronary disease were more likely to die of SUD than men.

\section{Demographics}

Our estimate of the incidence of sudden death is 42.4/ 100000 among male residents and 22.4/100 000 among female residents between the ages of 18 and 64 years. Only $1.5 \%$ of participants were both married and had a witnessed death, and there were significantly fewer married participants compared to all Wake County residents deceased in 2013 (33\% vs 44\%, $\mathrm{p}<0.01$ ). This supports the observation that marriage is a protective factor from sudden death.

The association between marriage and sudden death has been described previously, specifically that marriage had beneficial health effects for unemployed women by providing an alternative source of financial resources and social support. ${ }^{13}$ Within our cohort, African-Americans, especially males, accounted for a higher proportion of the study population over the age of 55 years; whites, especially women, accounted for a higher proportion of the population aged 55 years and under. Different racial make-up of older and younger age groups within our sample suggests that older age as a predictor for sudden death may be modified by race. African-Americans were over-represented in the cohort compared to the living population in Wake County ( $35 \%$ vs $21 \%$ ), which is partially accounted for by a significant excess of African-American women compared to living Wake County residents (43\% vs 23\%, $\mathrm{p}<0.001)$. Most participants had hypertension, with dyslipidaemia, smoking and BMI $>30 \mathrm{~kg} / \mathrm{m}^{2}$, and diabetes was also present in more than $30 \%$ of the cohort. Cardiomyopathy and $\mathrm{CAD}$ were less prevalent than expected.

There was a significant difference in estimated sudden death incidence between men and women in the cohort, but there was no difference in age at death or comorbidities such as hypertension or CAD. The cardioprotective effects of oestrogen may lead to less plaque and coronary disease. ${ }^{14}{ }^{15}$ However, the average age of men and women was 53, despite the presumed protective effect of oestrogen. The similarity of average age between men and women may be explained by the age of the cohort. The average age at menopause is 51 years, when women lose a substantial amount of oestrogen, ${ }^{11}$ and the average age of the women in our cohort is 53 .

\section{Strength of no timing criteria}

Our understanding of the aetiology and risk factors for sudden death is limited compared with other acute cardiovascular events such as myocardial infarction and stroke. Overlapping definitions of sudden death have contributed to variability in reported incidence rates and have impeded the study of sudden death aetiology

\begin{tabular}{lcclll}
\multicolumn{7}{l}{ Table 4 EMS reports of SUDDEN men and women } & Both & Men & Women & OR (95\% Cl) & p Value \\
\hline Dead on EMS arrival & $174(92)$ & $111(91)$ & $63(93)$ & $1.249(0.378$ to 4.344) & 0.791 \\
Death at primary residence & $166(87)$ & $102(84)$ & $64(94)$ & $3.137(0.953$ to 11.403) & $\mathbf{0 . 0 4 1}$ \\
Death in public area & $18(9)$ & $16(13)$ & $2(3)$ & $0.203(0.031$ to 0.964$)$ & $\mathbf{0 . 0 2 2}$ \\
Death unwitnessed & $178(94)$ & $111(91)$ & $67(99)$ & $6.640(0.856$ to 140.672) & 0.059 \\
Last seen alive over 24 $h$ before death & $20(11)$ & $15(12)$ & $5(7)$ & $0.571(0.172$ to 1.788) & 0.335 \\
Last seen alive less than 24 h before death & $61(32)$ & $40(33)$ & $21(31)$ & $0.927(0.466$ to 1.839) & 0.872 \\
Unknown hours since last seen alive & $109(57)$ & $67(55)$ & $42(62)$ & $1.326(0.693$ to 2.543) & 0.444 \\
\hline
\end{tabular}

Bolded $p$ value signifies a significant difference $(p<0.05)$. The values are given as $n(\%)$.

EMS, emergency medical services; SUDDEN, Sudden Unexpected Death in North Carolina project. 
Table 5 Cause of death on death certificate for SUDDEN men and women

\begin{tabular}{lccccc}
\hline & Both & Men & Women & OR (95\% Cl) & p Value \\
\hline Cardiac cause & $100(53)$ & $72(59)$ & $28(41)$ & $0.496(0.260$ to 0.945$)$ & 0.024 \\
Non-cardiac natural cause & $71(37)$ & $41(34)$ & $30(44)$ & $1.560(0.811$ to 3.000$)$ & 0.162 \\
Non-natural cause & $11(6)$ & $8(7)$ & $3(4)$ & $0.663(0.134$ to 2.882$)$ & 0.749 \\
Unknown cause & $8(4)$ & $1(1)$ & $7(10)$ & $14.000(1.671$ to 309.710$)$ & $\mathbf{0 . 0 0 3}$ \\
Substance abuse & $0(0)$ & $0(0)$ & $0(0)$ & NaN & NaN
\end{tabular}

Immediate (primary) cause of death was determined using Death Certificate ICD-10 codes: Cardiac code I, Non-cardiac natural codes A-H, J-R94, Non-natural codes V-Y, Unknown code R95-R99, Substance abuse codes T51-65. Cause of death on death certificate is preliminary and is considered incomplete until a year after the date of death. Bolded $p$ value signifies a significant difference $(p<0.05)$. The values are given as $\mathrm{n}(\%)$.

NaN, not a number; SUDDEN, Sudden Unexpected Death in North Carolina project.

and risk factors. ${ }^{16} 17$ The WHO's definition of sudden death focuses on sudden cardiac death, sudden cardiac arrest and SUD. Their definition describes sudden death as a witnessed sudden, unexpected death within $1 \mathrm{~h}$ of symptom onset or within $24 \mathrm{~h}$ of having been observed alive and symptom free. ${ }^{18}$ Although this definition is broad in defining the circumstances of death, studies that use the full definition, including the time restrictions, are prone to systematic exclusion of many victims. It may be 'more meaningful to define the specific characteristics surrounding cardiac arrest, and register and collect data in a standardised way, than to try to define the word 'sudden' in the context of death'. 6 18

Previous studies may have underestimated the incidence of SUD by systematic exclusion of people likely to die an unwitnessed death at an unknown time at home.

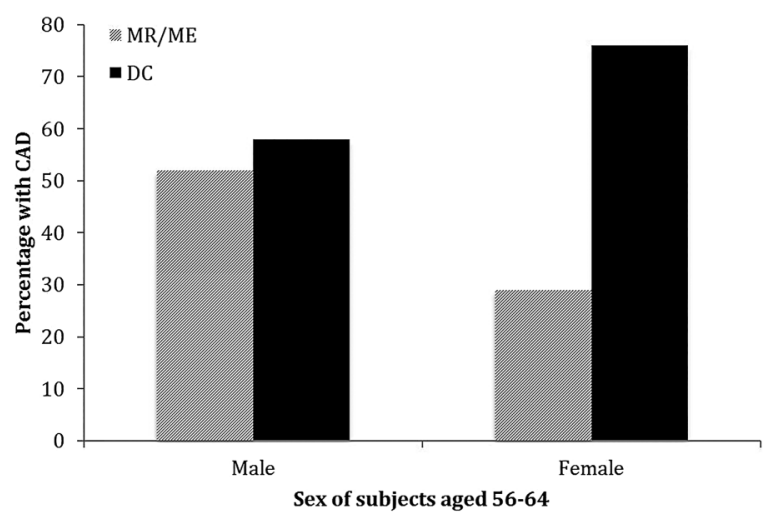

Figure 3 Proportion of Sudden Unexpected Death in North Carolina (SUDDEN) men and women with coronary artery disease (CAD) aged 56-64 years by source of medical datamedical record (MR) or medical examiner (ME) data. Death certificate data show that CAD is more likely to occur in older participants, especially older women. However, MR and ME data for the same participants show less CAD in older women. About $181(95 \%)$ of participants, $116(95 \%)$ men and $65(96 \%)$ women, had medical information available from hospital, physician or ME sources. All SUDDEN subjects had death certificates available. Cause of death by CAD on death certificates was determined using ICD-10 codes I 25.0, 25.1, 25.8 and 25.9. $p$ Values are calculated based on age groups $18-55$ vs $56-64$.
They have also tended to study racially homogeneous cohorts and so have missed, for example, the excess mortality in African-American women we have identified. We found more women dying of sudden death compared to previous studies. This might be explained by differences in case ascertainment and selection methods. ${ }^{19} 20$

\section{Death certificate data inconsistent with medical records}

We found frequent and important discrepancies in the death certificates compared to medical records. For example, there were no cases of substance abuse listed on the death certificate. However, toxicology screens were positive in $31 \%$ of medical examiner cases. CAD seemed over-represented in older particiapants. Coding inconsistencies are important issues as they can significantly impact estimates of disease incidence and resource allocation. ${ }^{21}$

In the Framingham Heart Study, 26-year follow-up of men and women aged 35-84 years indicated that CAD morbidity was twice as high in men as in women, and $60 \%$ of coronary events occurred in men. ${ }^{22}$ The onset of symptomatic CAD is typically about 10 years earlier in men, but CAD incidence in women increases rapidly at menopause. ${ }^{22}$ Analysis by age and coronary disease using medical records and medical examiner data in our cohort shows that women under age 55 years have more coronary disease than men of the same age. Most men with coronary disease were over the age of 55 years. This finding is inconsistent with previous research showing a growing risk of cardiovascular disease in older women. ${ }^{23}$ This suggests that coronary disease is a risk factor for SUD in younger women. However, the opposite result is seen when using death certificate data. As previously discussed, this may suggest inaccuracy in documentation on death certificates. Sudden death is not just a disease of men but may have great impact on younger women.

\section{Limitations}

The overall limitations of SUDDEN have been outlined previously. ${ }^{6}$ Our methodology created a comprehensive medical database, exemplified by acquisition of hospital or physician medical records on $68 \%$ of participants and death certificates for all 190 participants. 
We do not include all out-of-hospital victims. We do not include individuals who survived to the hospital or who died in the hospital, institutionalised patients, nonresidents of North Carolina, minors and anyone over the age of 65 years. However, survival from sudden death is low and the number of these sudden death cases should be low.

SUDDEN subjects are restricted to under age 65 years, which limits the study of sudden death in postmenopausal women. Given that the focus of our project is to assess preventable SUD, the age restriction may be understandable.

\section{CONCLUSIONS}

Using an epidemiological approach, we have identified the majority of sudden death victims are white unmarried men, with an unwitnessed death at home, and are over age 55 years with hypertension.

There was a significant difference in estimated incidence by gender but no difference in age or comorbidities. African-Americans and young women with CAD are at risk for sudden death.

Contributors MEL assisted with conception and design, analysis and interpretation of data, drafting of the manuscript, revising it critically for important intellectual content and final approval of the manuscript submitted. F-CL assisted with analysis and interpretation of data, revising the manuscript critically for important intellectual content and final approval of the manuscript submitted. PN assisted with conception and design, revising the manuscript critically for important intellectual content and final approval of the manuscript submitted. NM assisted with analysis and interpretation of data, revising the manuscript critically for important intellectual content. LM assisted with analysis and interpretation of data. AN assisted with analysis and interpretation of data. IP, EHC, JPM and RJSJr assisted with conception and design, revising the manuscript critically for important intellectual content and final approval of the manuscript submitted.

Funding The SUDDEN project is funded by individual, private donations, The Heart and Vascular Division of the University of North Carolina at Chapel Hill, and NC TraCS (National Center for Advancing Translational Sciences (NCATS), National Institutes of Health (NIH), grant award number 1UL1TR001111).

\section{Competing interests None declared.}

Ethics approval The SUDDEN project was reviewed by the Office of Human Research Ethics at UNC. The study was reviewed in accordance with federal regulations governing human subjects research (45 CFR 46, 45 CFR 164 (HPIAA), 21 CFR 50 and 56 (FDA) and 40 CFR 26 (EPA)) and has been approved by the UNC IRB (study \# 14-2036).

Provenance and peer review Not commissioned; externally peer reviewed.

Data sharing statement All data from the SUDDEN project are stored in an online database, REDCap. For access, please contact the study coordinator, IP, at irion_pursell@med.unc.edu, or the principal investigator, RJS, at ross_simpson@med.unc.edu.

Open Access This is an Open Access article distributed in accordance with the Creative Commons Attribution Non Commercial (CC BY-NC 4.0) license, which permits others to distribute, remix, adapt, build upon this work noncommercially, and license their derivative works on different terms, provided the original work is properly cited and the use is non-commercial. See: http:// creativecommons.org/licenses/by-nc/4.0/

\section{REFERENCES}

1. Nichol G, Thomas E, Callaway CW, et al. Regional variation in out-of-hospital cardiac arrest incidence and outcome. JAMA 2008;300:1423-31.

2. Yoon PW, Bastian B, Anderson RN, et al. Centers for Disease Control and Prevention (CDC). Potentially preventable deaths from the five leading causes of death-United States, 2008-2010. MMWR Morb Mortal Wkly Rep 2014;63:369-74. http://www.ncbi.nlm.nih.gov/ pubmed/24785982

3. Fishman GI, Chugh SS, Dimarco JP, et al. Sudden cardiac death prediction and prevention: Report from a national heart, lung, and blood institute and heart rhythm society workshop. Circulation 2010;122:2335-48.

4. Teodorescu C, Reinier K, Uy-Evanado A, et al. Survival advantage from ventricular fibrillation and pulseless electrical activity in women compared to men: The Oregon sudden unexpected death study. J Interv Card Electrophysiol 2012;34:219-25.

5. Vaartjes I, Hendrix A, Hertogh EM, et al. Sudden death in persons younger than 40 years of age: incidence and causes. Eur $J$ Cardiovasc Prev Rehabil 2009;16:592-6.

6. Nanavati PP, Mounsey JP, Pursell IW, et al. Sudden Unexpected Death in North Carolina (SUDDEN): methodology review and screening results. Open Heart 2014;1:e000150. http://openheart.bmj. com/cgi/doi/10.1136/openhrt-2014-000150 http://dx.doi.org/10.1136/ openhrt-2014-000150

7. Albert $\mathrm{CM}, \mathrm{Chae} \mathrm{CU}$, Grodstein $\mathrm{F}$, et al. Prospective study of sudden cardiac death among women in the United States. Circulation 2003;107:2096-101.

8. Kucharska-Newton AM, Couper DJ, Pankow JS, et al. Diabetes and the risk of sudden cardiac death, the Atherosclerosis Risk in Communities study. Acta Diabetol 2010;47(Suppl 1):161-8.

9. Chambless LE, Heiss G, Folsom AR, et al. Association of coronary heart disease incidence with carotid arterial wall thickness and major risk factors: the Atherosclerosis Risk in Communities (ARIC) Study, 1987-1993. Am J Epidemiol 1997;146:483-94.

10. Goraya TY, Jacobsen SJ, Kottke TE, et al. Coronary heart disease death and sudden cardiac death: A 20-year population-based study. Am J Epidemiol 2003;157:763-70.

11. Kannel WB, Wilson PW. Risk factors that attenuate the female coronary disease advantage. Arch Intern Med 1995;155:57-61.

12. Austad SN. Why women live longer than men: Sex differences in longevity. Gend Med 2006;3:79-92.

13. Waldron I, Hughes ME, Brooks TL. Marriage Protection and Marriage Selection-Prospective Evidence for Reciprocal Effects of Marital Status and Health. Soc Sci Med 1996;43:113-23.

14. Roeters van Lennep JE, Westerveld HT, Erkelens DW, et al. Risk factors for coronary heart disease: implications of gender. Cardiovasc Res 2002;53:538-49.

15. Mendelsohn ME. Protective effects of estrogen on the cardiovascular system. Am. J. Cardiol 2002;89:12E-17E; discussion 17E-18E.

16. Kong MH, Fonarow GC, Peterson ED, et al. Systematic review of the incidence of sudden cardiac death in the United States. J Am Coll Cardiol 2011;57:794-801.

17. Bertoia ML, Allison MA, Manson JE, et al. Risk factors for sudden cardiac death in post-menopausal women. J Am Coll Cardiol 2012;60:2674-82.

18. Death WSG on SC, Organization WH. Sudden cardiac death : report of a WHO scientific group [meeting held in Geneva from 24 to 27 October 1984]. 1985. http://apps.who.int//iris/handle/10665/39554 (accessed 7 Apr 2015).

19. Chugh SS, Uy-Evanado A, Teodorescu C, et al. Women have a lower prevalence of structural heart disease as a precursor to sudden cardiac arrest. The Ore-SUDS (Oregon Sudden Unexpected Death Study). J Am Coll Cardiol 2009;54:2006-11.

20. $\mathrm{Ni} \mathrm{H}$, Coady S, Rosamond W, et al. Trends from 1987 to 2004 in sudden death due to coronary heart disease: the Atherosclerosis Risk in Communities (ARIC) study. Am Heart J 2009;157:46-52.

21. Rhodes $\mathrm{H}$. Measuring the Risks and Causes of Premature Death. 2015. http://www.ncbi.nlm.nih.gov/books/NBK279971/ (accessed 7 Apr 2015).

22. O'Donnell CJ, Elosua R. [Cardiovascular risk factors. Insights from Framingham Heart Study]. Rev Esp Cardiol 2008;61: 299-310.

23. Mosca L, Manson JE, Sutherland SE, et al. Cardiovascular disease in women: a statement for healthcare professionals from the American Heart Association. Writing Group. Circulation 1997;96:2468-82. http://circ.ahajournals.org/content/96/7/2468. long\#content-block (accessed 12 Feb 2015). 